\title{
Study on Occupational Health and Safety Impact of Surfactant-Grafted Polyacrylamide Used in Oilfields
}

\author{
Tingting Jiang1, Baohui Wang' , Aijun Wang', Hongjing Han'1, Hongjun Wu ${ }^{1}$ \\ ${ }^{1}$ Institute of New Energy Chemistry and Environmental Science, College of Chemistry \& Chemical Engineering, \\ Northeast Petroleum University, Daqing, China \\ ${ }^{2}$ Xinjiang Petroleum Investigation Design and Research Institute (Co., Ltd.), Karamay, China \\ Email: jiangtingting82@163.com
}

Received 26 July 2015; accepted 14 August 2015; published 17 August 2015

Copyright $@ 2015$ by authors and Scientific Research Publishing Inc.

This work is licensed under the Creative Commons Attribution International License (CC BY).

http://creativecommons.org/licenses/by/4.0/

(c) (i) Open Access

\begin{abstract}
Surfactant-grafted Polyacrylamide (S-PAM) serves as a novel oil displacement agent in oilfield. Its toxicity and the impact on the occupational safety are unclear. The analysis on composition and chemical structure of S-PAM shows that due to its instability the harmful ammonia gas may be generated during the operation of S-PAM or high temperature. The toxicity and safety evaluation of the S-PAM were analyzed, and suggestions on the protection were proposed. It can provide a safe and healthy working environment for the operators with enormous social and economic benefits.
\end{abstract}

\section{Keywords}

Surfactant-Grafted Polyacrylamide, Occupational Health, Oilfield

\section{Introduction}

With the increasing sophistication of EOR, polymer flooding technology is more and more widely used in oilfield development [1]-[3]. At present, the EOR method was used in oilfield, which mainly includes polymer flooding, compound flooding (polymer-surfactant) and ASP flooding (polymer-surfactant-alkali composite). There are varying degrees of problems in the application of the above flooding, for example, polymer flooding remains high interfacial tension between the oil fluid and crude oil; basically no solubilization and emulsification capacity is for crude oil; the current polymer doesn't have the anti-salt, anti-bacterial and anti-oxidation function, and is not suitable for preparation with sewage. Different components of chemicals in binary or ternary 
chemical flooding are quite different in the proliferation and migration in the reservoir, resulting in "chromatographic effect" and undesirable "synergies effect", and resulting in enhanced oil recovery minor [4]-[6]. In addition, strong base additives also lead to severe scaling in many other aspects during the recovery process; there are some inconveniences to the production [7].

A new type of compound, graft copolymer surfactant (referred to as polymer surfactant), which combines the advantages of polymer and surfactant, has all the advantages of tackifying, reducing the flow ratio, expanding the sweep efficiency, reducing the interfacial tension, improving the solubilization and emulsifying capacity for crude oil, and aggregating into a single component of a new chemical flooding agent [8] [9]. As the field tests of polymer surfactant used for EOR are carried out, the results show that the polymer surfactant is very different from the general polymers, which are used for EOR in the same field, but with differences of the production, type, structure, component, physicochemical properties and toxicity. The toxicity may come from the residual acrylamide monomer in the production process and entrained toxic heavy metals, which impact the applications, health and safety, in order to clarify its physicochemical properties and potential impacts on the operator health during production [10].

This study analyzed the physicochemical properties and toxicity of S-PAM using chemical analysis method, instrument analysis method etc. and analyzed the occupational health and safety impact in order to provide a safe and healthy working environment for the operators.

\section{Chemical Structure}

Relevant data reveal that Surfactant-grafted Polyacrylamide (S-PAM) has a framework constituted by ordinary polyacrylamide hydrocarbon chains. The aqueous solution of S-PAM is provided with the physical and chemical properties of the polymer and surfactant, as well as the new properties which are absent in the two agents. Chemical analysis implied that, Lianhua S-PAM polymerized the nonionic and cationic surfactants. In S-PAM analysis field, infrared spectra were mainly used for quantitative analysis, especially for the quantitative analysis of the functional groups of S-PAM. According to the characteristic absorption of compounds, it was aware of the functional groups in the compounds, which were conductive to determine and verify the types of related compounds. This section used the infrared spectrum analysis method to analyze the compositions of the surfactant.

\subsection{Experimental}

The S-PAM was used in this experiment: Daqing Refining \& Chemical Company S-PAM (Lianhua type III), which is called Lianhua S-PAM.

To determine the group types in the surfactants produced by Daqing, Btuker Tensor 27 infrared spectroscopy was used for analysis.

\subsection{Results and Discussion}

The compositions of S-PAM were analyzed using infrared spectrum in this section. Figure 1 shows the infrared spectra of the S-PAM.

By means of chemical analysis, IR spectra analysis, as well as related data concerning S-PAM synthesis, the chemical structures of S-PAM are indicated as follows:

The structure and compositions of Lianhua S-PAM:<smiles>[Y]NC(=O)C(CC(C)C)CC(CC(CCC)C(N)=O)C(=O)O[X]</smiles>

where X: Alkyl ethers- $\left(\mathrm{CH}_{2} \mathrm{CH}_{2} \mathrm{O}\right)_{\mathrm{m}}-\mathrm{R}$,nononic

sulphosalts $-\underset{\mathrm{CH}_{2}-\mathrm{SO}_{3} \mathrm{Na}}{\left(\mathrm{CH}_{2}\right)_{\mathrm{n}} \mathrm{CH}_{3}}$, anionic 


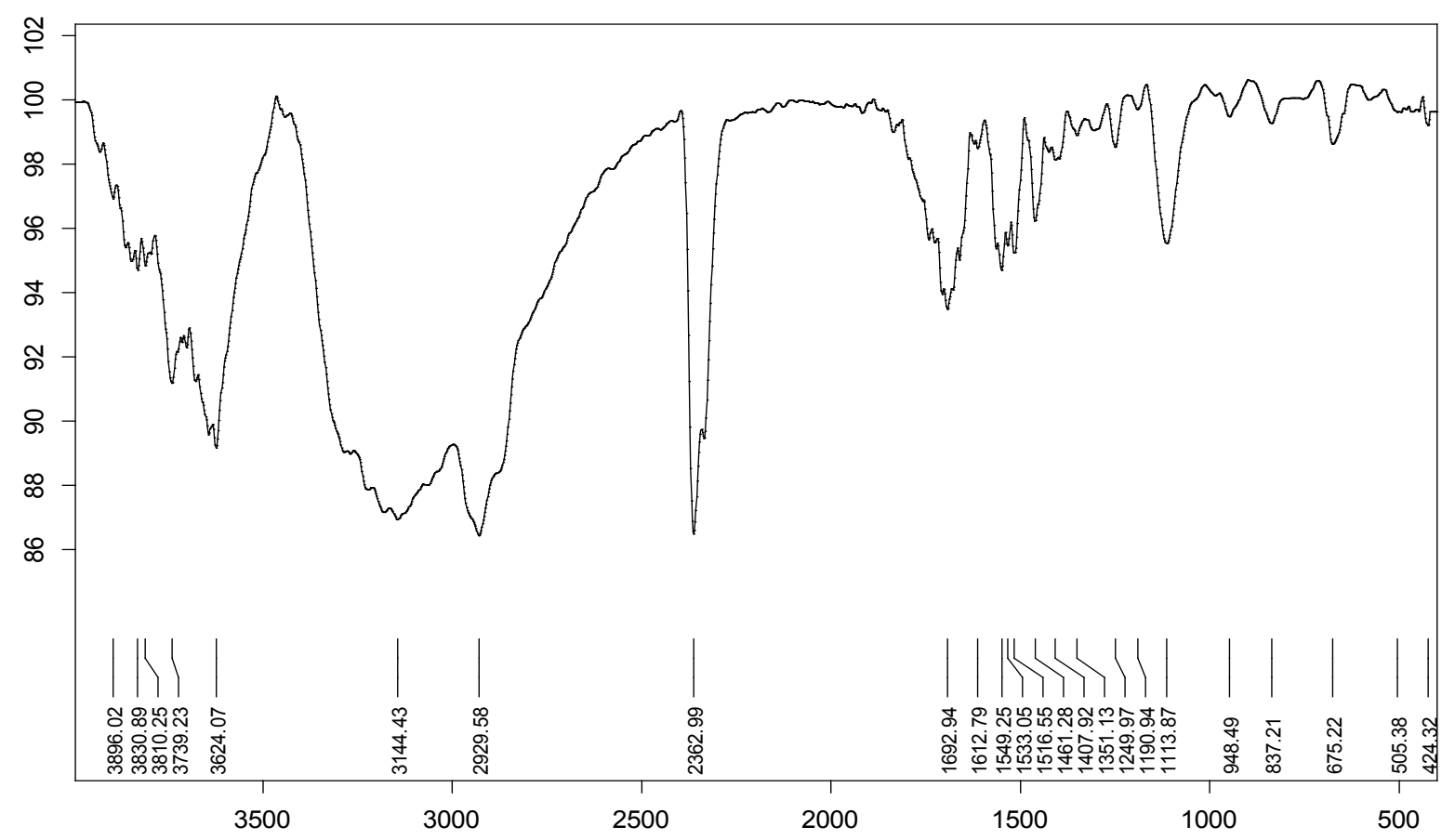

Figure 1. The infrared spectra of Lianhua S-PAM.

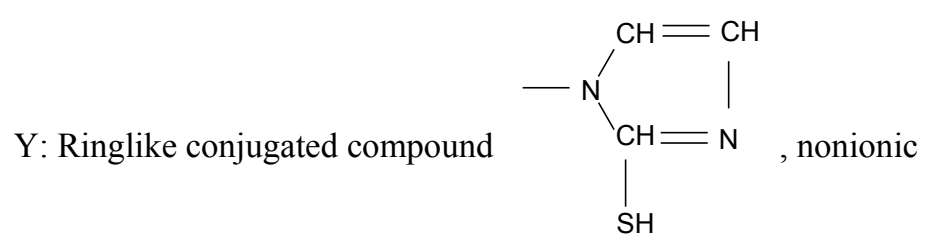

Plolyester $-\mathrm{CH}=\mathrm{CH}-\stackrel{\mathrm{O}}{\mathrm{C}}-\mathrm{O}-\left(\mathrm{CH}_{2}\right) \mathrm{nCH}_{3}$, nonionic

Carboxylates $-\mathrm{CH}=\mathrm{CH}-\mathrm{C}-\mathrm{ONa}$, anionic

\section{Toxicity and Safety Evaluation}

\subsection{Toxicologic Study}

Toxicology research method is traditionally divided into two broad categories, which are in vitro tests and in vivo tests. In vivo tests are adopted in this experiment.

\subsubsection{Experimental}

Lianhua S-PAM. was used in this experiment. Experimental animals and standard particle feed were provided by Heilongjiang University of Chinese Medicine. There are 20 healthy s.d. rats with half males and half females used in this section, whose weight are $170-220 \mathrm{~g}$.

All the rats were investigated feeding a week before experiment, fasting 8 hours before dosing which are allowed to drink.

Dissolved $20 \mathrm{~g}$ S-PAM powders into $1200 \mathrm{ml}$ water $(0.0167 \mathrm{~g}$ S-PAM per $\mathrm{ml})$. Fully stirred the solution to sticky transparent paste. The rats were tested by oral perfusion at same doses $(5 \mathrm{ml})$ per 2 hours for 24 hours respectively.

\subsubsection{Results and Discussion}

The 14-day-feed-mice test was demonstrated positive results. That indicated the polymer surfactant was rela- 
tively non-toxic under the maximum dose (feeding the mice 10 - 12 times in 24 hours, $5 \mathrm{~mL}$ each feeding).

\subsection{Safety Evaluation of S-PAM}

Two origins of S-PAM were used in this experiment: Daqing Refining \& Chemical Company S-PAM (Lianhua type III), which is called Lianhua S-PAM; Shanghai Haibo company S-PAM (Haibo type III), which is called Haibo S-PAM. The main instrument: AMMONIA METER Z-800.

First of all, ammonia release of two solid S-PAMs was measured at different temperatures respectively. The highest content of ammonia was measured, which was converted to mass of ammonia evolution per gram of solid S-PAM. The ammonia release of S-PAM solutions prepared by clean water and oilfield water were measured during the dissolving time and storage time at room temperature. The highest content of ammonia was converted to mass of ammonia evolution per Liter of S-PAM solution.

\section{Emissions of Solid S-PAM}

Ammonia emissions of two solid S-PAMs were measured at different temperatures respectively. The highest content of ammonia was measured, which was converted to mass of ammonia evolution per gram of solid S-PAM. Figure 2 experimentally shows the data measured at different temperatures.

The experiment results show the following conclusions:

1) With increasing temperature, ammonia emissions of two solid S-PAMs are on the rise.

2) Ammonia emissions of Lianhua S-PAM per gram increases slowly with rising temperature; the amount of Haibo has a slow growth at first, which has a rapid growth when the temperature is higher than $45^{\circ} \mathrm{C}$.

3) Ammonia emissions of Haibo S-PAM per g are higher than Lianhua.

\subsection{Emissions of S-PAM Solution}

\subsubsection{Clean Water Prepared S-PAM Solution}

The two S-PAM solutions were prepared at a concentration of $1000,1200 \mathrm{ppm}$ respectively with clean water. Ammonia release was measured during the dissolving time and storage time at room temperature. The highest content of ammonia was converted to mass of ammonia evolution per Liter of S-PAM solution.

Figure 3 and Figure 4 experimentally show the following conclusions:

1) The change in magnitude of ammonia release is larger during the dissolving time, which is smaller at storage time.

2) The ammonia release of Lianhua is higher than Haibo.

3) The ammonia release is larger with higher concentration.

The same law was not showing in solid S-PAM and solution. After analyzing the main reason is that the viscosity of solution Lianhua is greater than Haibo. And ammonia is highly soluble in water, which is more soluble

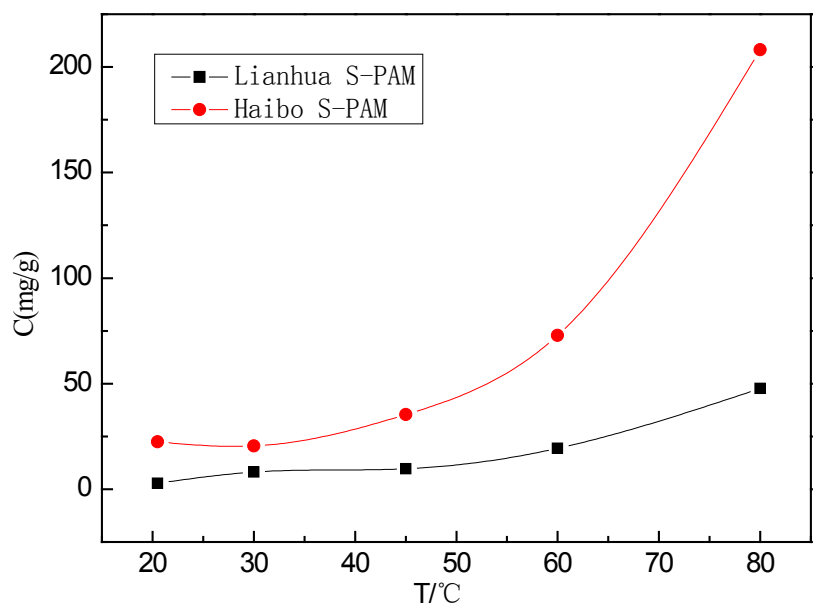

Figure 2. Ammonia emissions of two solid S-PAM at different temperatures. 


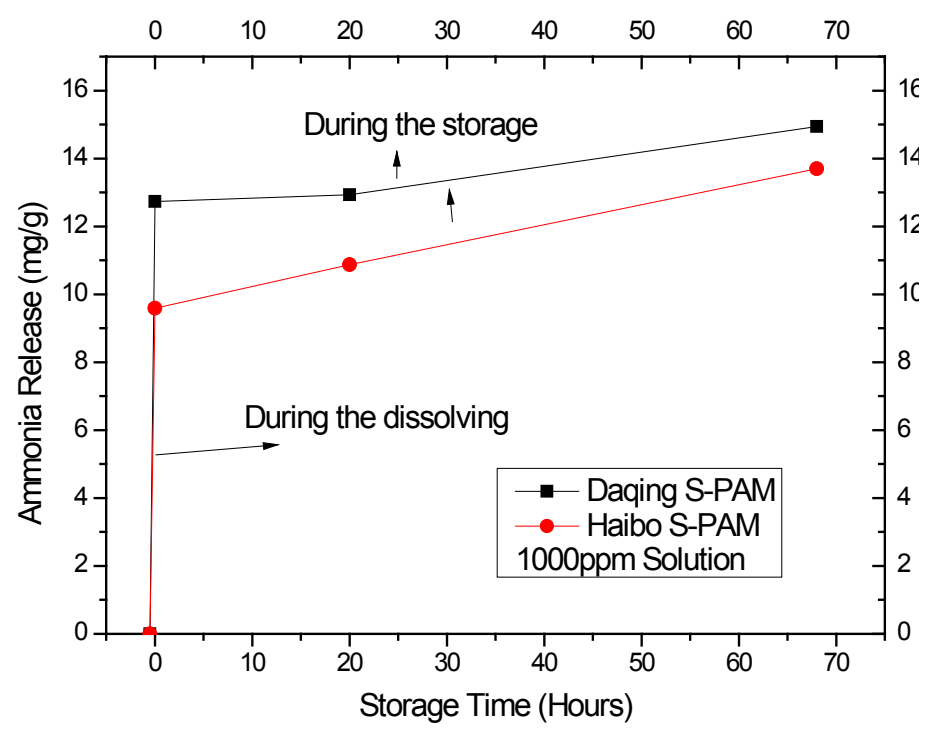

Figure 3. The ammonia release of two S-PAM solutions.

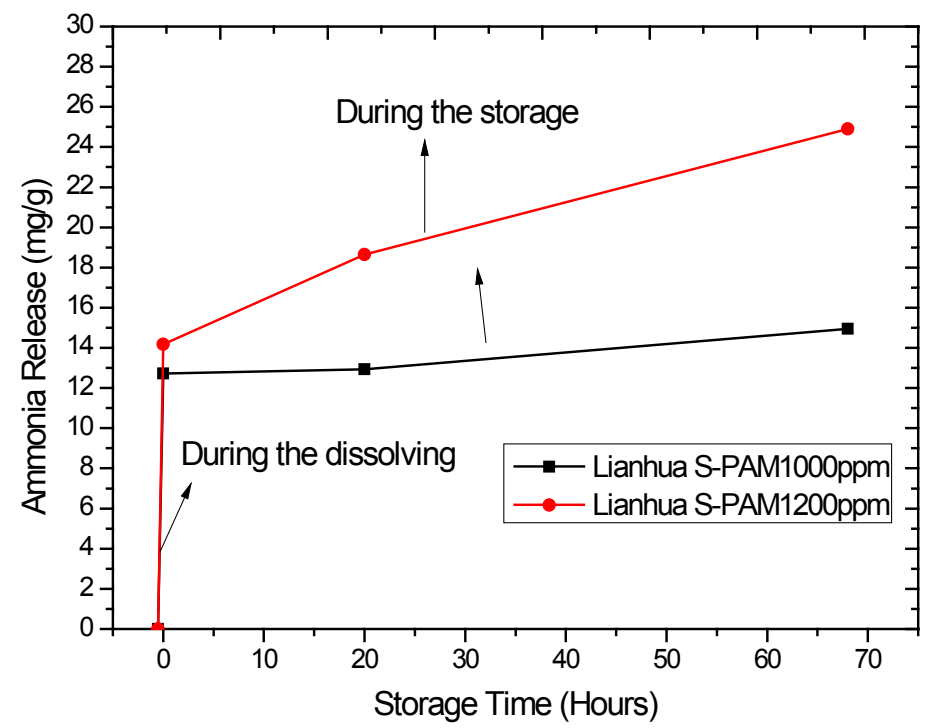

Figure 4. The ammonia release of Lianhua S-PAM solution at different concentrations.

in a solution of low viscosity. Therefore ammonia emission Lianhua is higher than Haibo in monitoring process.

\subsubsection{Oilfield Water Prepared S-PAM Solution}

Oilfield water and S-PAM mother liquor used in this experiment were retrieved from oilfield. Specific preparation process is to simulate the process of site preparation. Mother liquor $(3000 \mathrm{mg} / \mathrm{L})$ was obtained by diluting S-PAM solution $(1200 \mathrm{mg} / \mathrm{L}$ and $1500 \mathrm{mg} / \mathrm{L})$ using oilfield water. The highest content of ammonia was converted to mass of ammonia evolution per Liter of S-PAM solution.

Figure 5 experimentally shows the following conclusions:

1) The change in magnitude of ammonia release is more larger during the dissolving time, which is smaller at storage time.

2) The ammonia release of Lianhua is higher than Haibo.

3) In the time range of monitoring, ammonia emissions of Lianhua S-PAM are slightly higher than Haibo S-PAM both in clean water and oilfield water solution. 


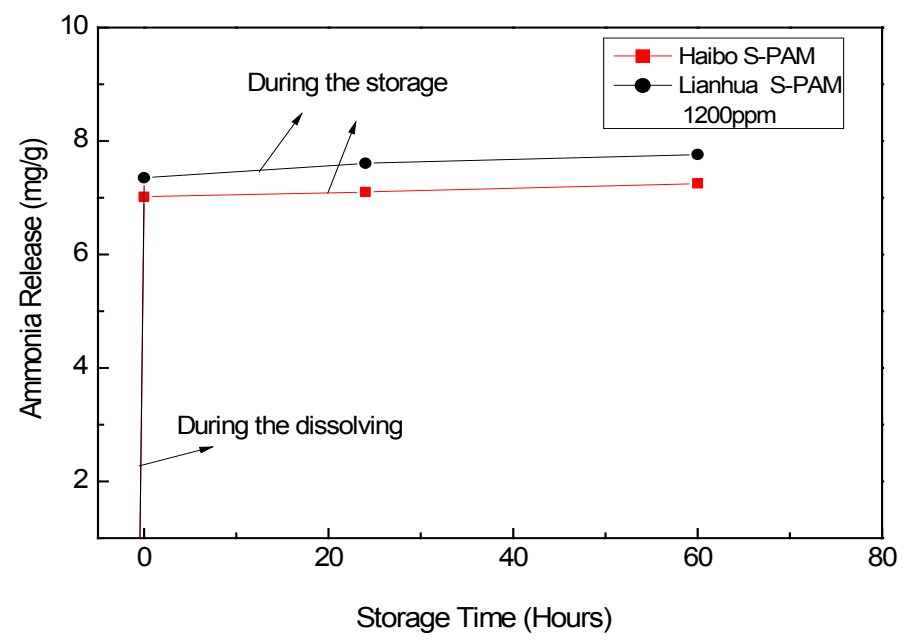

Figure 5. The curve of ammonia emissions of oilfied water prepared SPAM solution.

\section{Analysis of Occupational Health and Safety Impact}

It was found that ammonia emissions of S-PAM are considerably high in feed tank mouth. We must earnestly do the protection work of ammonia at workshop. In order to ear hazards and problems of S-PAM for workers in the storage and dissolving process.

The environment of ammonia concentration and the length of contact time determine the harm to health of ammonia. The infringement way of ammonia is mainly through respiratory inhalation, accompanied by the eyes and skin damage, seriously can appeared acute respiratory distress syndrome.

The categories of dust and chemical are mentioned in the occupational-disease-inductive factors classification catalogue, which was issued by the ministry of health on 11 March 2002. The ammonia is also in chemical category. Ammonia was clearly identified for the domain pollutant in the production environment. The infringement way of ammonia is mainly through respiratory inhalation with eyes and skin damage.

\section{Conclusions}

Analysis on the compositions of S-PAM implied that Lianhua S-PAM polymerized the nonionic and cationic surfactants, while Haibo S-PAM polymerized the nonionic surfactants on the main chain of polyacrylamide.

In the time range of monitoring, ammonia emissions of Lianhua S-PAM are slightly higher than Haibo SPAM both in clean water and oilfield water solution.

Based on the above data and the relative methods, suggestions on the protection were proposed. It can provide a safe and healthy working environment for the operators with enormous social and economic benefits.

\section{References}

[1] Ge, G.Z., Wang, J.Y. and Wang, Y.L. (2001) Polymer Flooding and Related Chemical Flooding Progress. Oilfield Chemistry, 18, 282-284. (In Chinese)

[2] Parrish, B., Breitenkamp, R.B. and Emrick, T. (2005) PEG- and Peptide-Grafted Aliphatic Polyesters by Click Chemistry. Journal of the American Chemical Society, 127, 7404-7410. http://dx.doi.org/10.1021/ja050310n

[3] Li, H.Y., Jérôme, R., Lecomte, Ph., et al. (2007) Combination of Ring-Opening Polymerization and "Click" Chemistry for the Synthesis of an Amphiphilic Tadpole-Shaped Poly( $\varepsilon$-caprolactone) Grafted by PEO. Macromolecules, 40, 824831. http://dx.doi.org/10.1021/ma062488f

[4] Zhang, J.Y., Zhou, Y.M., Liu, S.Y., et al. (2008) Polyion Complex Micelles Possessing Thermoresponsive Coronas and Their Covalent Core Stabilization via "Click" Chemistry. Macromolecules, 41, 1444-1454. http://dx.doi.org/10.1021/ma702199f

[5] Wang, D.M., Xia, H.F., Liu, Z.C., et al. (2001) Study of the Mechanism of Polymer Solution with Viscoelastic Behaviour Increasing Microscopicoil Displacement Efficiency and the Forming of Steady "Oil Thread" Flow Channel. 
SPE68732. Soc Petrol Engrs Paper.

[6] Hu, B.Z. (1997) Production Engineering of Polymer Flooding. Petroleum Industry Press, Beijing, 70-72. (In Chinese)

[7] Saad, N., Cullick, A.S. and Honarpour, M.M. (1995) Immiscible Displacement Mechanisms and Scale-Up in the Presence of Small-Scale Heterogeneities. SPE30779, SPE Annual Technical Conference and Exhibition, Dallas, 22-25 October 1995.

[8] Thompson, K.E. and Kwon, O. (1998) Selective Conformance Control in Heterogeneous Reservoirs Using Unstable, Reactive Displacements. SPE39672, SPE/DOE Enhanced Oil Recoverys Symposium, Tulsa, 19-22 April 1998.

[9] Wang, Y.M., Wang, Y.J. and Lu, X.B. (2008) “Grafting-From” Polymerization for Uniformly Bulk Modification of Pre-Existing Polymer Materials via a Supercritical-Fluid Route. Polymer, 49, 474-480. http://dx.doi.org/10.1016/j.polymer.2007.11.028

[10] Zhao, J.R., Li, J.Y., Feng, Y., et al. (2007) A Novel Approach to Synthesis of Functional CPVC and CPE or Graft Copolymers-In Situ Chlorinating Graft. Polymers for Advanced Technologies, 18, 822-828. http://dx.doi.org/10.1002/pat.941 